\title{
Optimization of underwater wet welding process parameters using neural network
}

\author{
Joshua Emuejevoke Omajene*, Jukka Martikainen, Huapeng Wu and Paul Kah
}

\begin{abstract}
Background: The structural integrity of welds carried out in underwater wet environment is very key to the reliability of welded structures in the offshore environment. The soundness of a weld can be predicted from the weld bead geometry.

Methods: This paper illustrates the application of artificial neural network approach in the optimization of the welding process parameter and the influence of the water environment. Neural network learning algorithm is the method used to control the welding current, voltage, contact tube-to-work distance, and speed so as to alter the influence of the water depth and water environment.

Results: The result of this work gives a clear insight of achieving proper weld bead width $(W)$, penetration $(P)$, and reinforcement $(R)$.

Conclusions: An interesting implication of this work is that it will lead to a robust welding activity so as to achieve sound welds for offshore construction industries.
\end{abstract}

Keywords: Backpropagation; Bead geometry; Neural network; Process parameter; Underwater welding

\section{Background}

The differences in the weld quality for underwater welding as compared to air welding have made it very necessary to model an artificial neural network (ANN) which is capable of solving difficult and complex problems. The weld bead geometry of an underwater wet welding can be predicted by the neural network control of the input parameters as shown in Figure 1. The water surrounding the weld metal results in a fast cooling of the weld, thereby reducing the ductility and tensile strength of the weld metal by $50 \%$ and $20 \%$, respectively (Brown and Masubuchi 1975). The effect of the water environment and the water depth on the welding process parameters significantly affects the quality of welds achieved underwater. The diffusible hydrogen contents are increased at lower water temperature for lower oxygen content. The increase in the diffusible hydrogen content leads to increase in the susceptibility of steels to hydrogen-assisted cracking (Johnson 1997). The water depth plays a role in the stability of the welding arc. Increased water depth constricts the

\footnotetext{
* Correspondence: Joshua.omajene@yahoo.com

LUT Mechanical Engineering, Lappeenranta University of Technology, P.O. Box 20, Fl-53851 Lappeenranta, Finland
}

arc, thereby resulting in an increased current and voltage as the water depth increases. An increasing water depth decreases the operating process parameter space (Liu et al. 1993). This paper proposes suitable means of optimizing the welding process parameter using a neural network so as to minimize the effect of the cooling rate and water depth in underwater welding. The main goal is to achieve a weld bead geometry which will give the weld metal the recommended structural integrity as prescribed by the underwater welding specification code AWS D3.6M:2010 (AWS 2010).

\section{Methods \\ Underwater welding}

Underwater welding is used for the repair welding of ships and offshore engineering structures like oil drilling rigs, pipelines, and platforms. The commonly used underwater welding processes nowadays are shielded metal arc welding (SMAW) and flux cored arc welding (FCAW). The water surrounding the weld metal reduces the mechanical properties of weld done underwater due to the effect of the fast cooling rate of the weld. Heat loss by conduction from the 


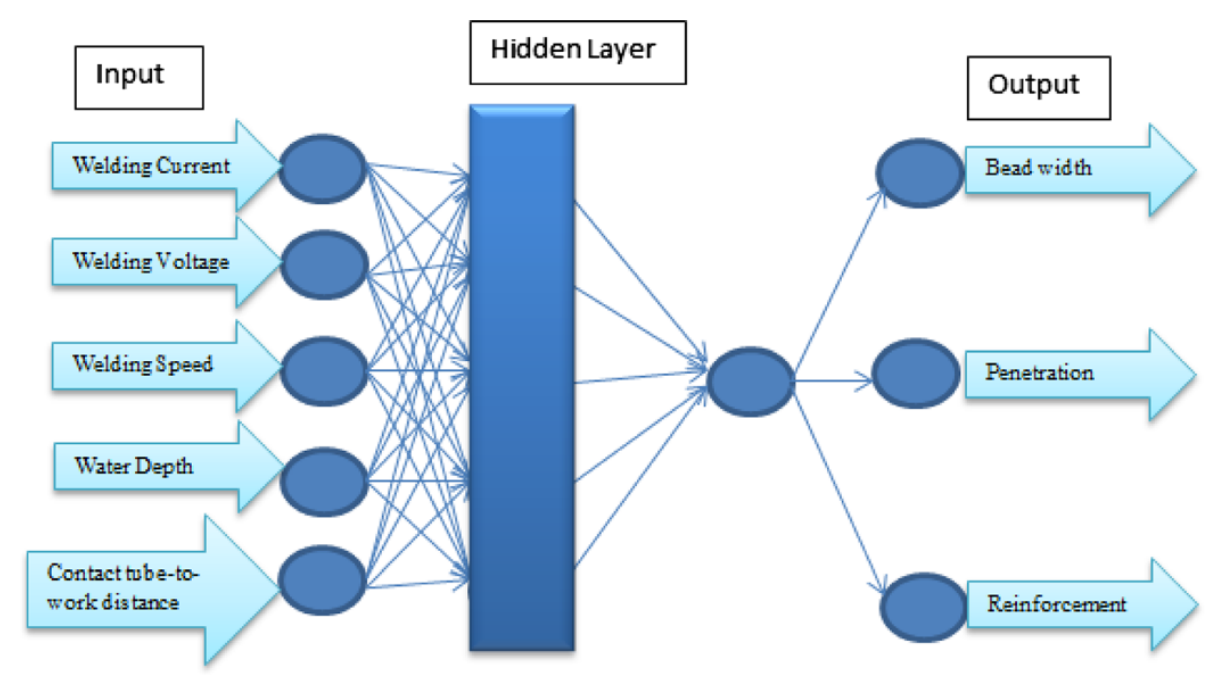

Figure 1 Welding input vs output parameters.

plate surface into the moving water environment and heat loss by radiation are the major heat losses in underwater welding. Underwater welding requires a higher current for the same arc voltage to achieve a higher heat input as compared to air welding. The fast cooling rate of underwater welding results in the formation of constituents such as martensite and bainite for conventional welding of steels. These constituents lead to a high-strength, brittle material and susceptibility to hydrogen-induced cracking. The weld bead shape for underwater wet welding are more spread out and less penetrating than air welds. Underwater welding arc is constricted at increased depth or pressure. However, welding in shallow depth is more critical than that in higher depth. The unstable arc results in porosity which affects the soundness of the weld. Weld metal carbon content increases with increase in water depth. Also, manganese and silicon which are deoxidizers are increasingly lost at increased water depth (Omajene et al. 2014).

\section{Artificial neural network}

A neural network is a data modeling tool that captures and represents complex input/output relationships. A neuron gets signals from its input links, computes a new activation level, and sends an output signal through the output link(s). The learning algorithm is the procedure to modify the synaptic weights of the network to achieve the desired objective of the design. Weights are the basic means of long-term memory in artificial neural networks. The multilayer perceptron neural network (NN) is the most applicable network architecture in use today.

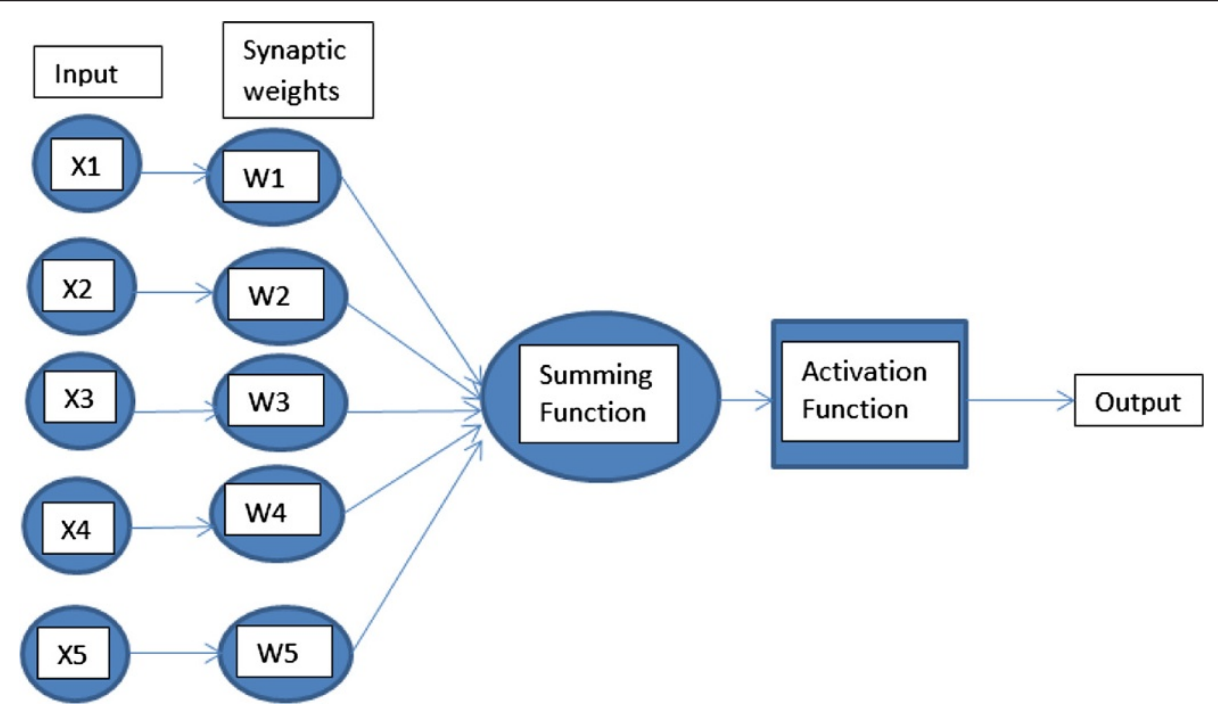

Figure 2 Multilayer perceptron. 


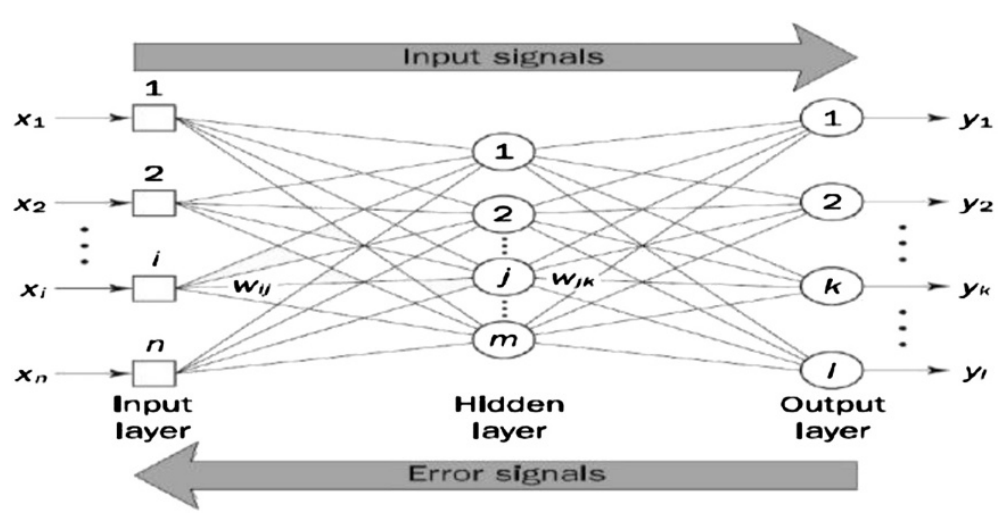

Figure 3 Three-layer backpropagation neural network (Negnevetsky 2005).

Each unit as shown in Figure 2 undergoes a biased weighted sum of its inputs and passes it through an activation function to produce its output. These units are arranged in a layered feed forward topology. The multilayer perceptron neural network learns using backpropagation algorithm as shown in Figure 3. In backpropagation algorithm, the input data is repeatedly presented to the neural network. In each presentation, the output of the neural network is compared to the desired output, thereby computing an error signal. The error is presented back to the neural network to adjust the weights in a manner that the error decreases with each iteration and the neural network model gets closer to the desired target. Figure 3 illustrates a neural network using the backpropagation algorithm whereby the weight is changed as the iteration increases, thereby reducing the error and getting closer to the desired target (Al-Faruk et al. 2010; Juang et al. 1998).

\section{Summary of the backpropagation training algorithm}

The summary of the backpropagation training algorithm is illustrated as follows (Negnevetsky 2005).

Step 1: Initialization

$$
\left(-\frac{2.4}{F_{i}},+\frac{2.4}{F_{i}}\right)
$$

Set the weights and threshold levels of the network to uniformly random numbers distributed in small range. $F_{i}$ is the total number of inputs of neuron $i$ in the network.

Table 1 Experimental data adapted from (Shi et al. 2013)

\begin{tabular}{|c|c|c|c|c|c|c|c|c|c|c|c|}
\hline \multirow{3}{*}{$\begin{array}{l}\text { Serial } \\
\text { number }\end{array}$} & \multirow{2}{*}{\multicolumn{4}{|c|}{ Process parameters }} & \multirow{3}{*}{$\begin{array}{l}\text { Water } \\
\text { depth } \\
H(\mathrm{~m})\end{array}$} & \multirow{2}{*}{\multicolumn{3}{|c|}{ Bead geometry }} & \multirow{2}{*}{\multicolumn{3}{|c|}{$\begin{array}{c}\text { Error }=\text { Output }(W, P, R)-\text { Target } \\
\text { Target }=0\end{array}$}} \\
\hline & & & & & & & & & & & \\
\hline & $I(\mathrm{~A})$ & $U(\mathrm{~V})$ & $v(\mathrm{~m} / \mathrm{s})$ & $D(\mathrm{~m})$ & & $W(\mathrm{~m})$ & $P(\mathrm{~m})$ & $R(\mathrm{~m})$ & $\Delta W(\mathrm{~m})$ & $\Delta P(\mathrm{~m})$ & $\Delta R(\mathrm{~m})$ \\
\hline 1 & 280 & 28 & 10 & 20 & 40 & 10.4 & 2.5 & 4.3 & 0.0061 & 0.0091 & 0.0016 \\
\hline 2 & 320 & 32 & 6 & 20 & 20 & 12.5 & 3.8 & 8 & 0.0022 & -0.0394 & 0.0998 \\
\hline 3 & 300 & 32 & 10 & 22 & 60 & 10.4 & 3 & 4 & -0.3280 & -1.1397 & -0.5471 \\
\hline 4 & 340 & 28 & 6 & 22 & 0.1 & 13.9 & 3.5 & 3 & 1.6136 & -0.1071 & -0.7470 \\
\hline 5 & 280 & 30 & 6 & 24 & 60 & 12.9 & 3.7 & 6.1 & 0.0223 & -0.0104 & 0.0083 \\
\hline 6 & 320 & 26 & 10 & 24 & 0.1 & 11.6 & 1.8 & 2 & 0.0093 & 0.0650 & 0.0269 \\
\hline 7 & 300 & 26 & 6 & 18 & 40 & 12 & 2.9 & 5 & -0.0177 & -0.0126 & 0.0080 \\
\hline 8 & 340 & 30 & 10 & 18 & 20 & 9.4 & 4.2 & 4.3 & -0.0193 & 0.1365 & 0.0038 \\
\hline 9 & 280 & 26 & 12 & 22 & 20 & 8.9 & 1.7 & 4.5 & -0.3662 & -1.0633 & -0.2616 \\
\hline 10 & 320 & 30 & 8 & 22 & 40 & 11.8 & 3.3 & 4.8 & -0.0323 & 0.0312 & 0.0007 \\
\hline 11 & 300 & 30 & 12 & 20 & 0.1 & 12.8 & 1.7 & 1.9 & -0.0363 & -0.1342 & -0.0876 \\
\hline 12 & 340 & 26 & 8 & 20 & 60 & 9.5 & 3.4 & 4.8 & 0.0169 & -0.0132 & 0.0008 \\
\hline 13 & 280 & 32 & 8 & 18 & 0.1 & 12.5 & 2 & 2 & 0.0089 & 0.0151 & 0.0553 \\
\hline 14 & 320 & 28 & 12 & 18 & 60 & 7.9 & 2.7 & 4.9 & -0.8149 & -0.9025 & 1.8429 \\
\hline 15 & 300 & 28 & 8 & 24 & 20 & 10.1 & 3.1 & 4.9 & -0.0211 & 0.0055 & -0.0067 \\
\hline 16 & 340 & 32 & 12 & 24 & 40 & 10 & 3 & 4 & 0.0011 & -0.0140 & 0.0213 \\
\hline
\end{tabular}


Step 2: Activation

Activate the backpropagation neural network by applying inputs $x_{1}(p), x_{2}(p), \ldots, x_{n}(p)$ and desired output $y_{d, 1}(p)$, $y_{d, 2}(p), \ldots, y_{d, n}(p)$.

(a) Calculate the actual outputs of the neurons in the hidden layer:

$$
y_{j}(p)=\operatorname{sigmoid}\left[\sum_{i=0}^{n} x_{i}(p) * w_{i j}(p)-\theta_{j}\right]
$$

where $n$ is the number of inputs of neuron $j$ in the hidden layer and sigmoid is the sigmoid activation function.

(b)Calculate the actual outputs of the neurons in the output layer.

(c) $y_{k}(p)=\operatorname{sigmoid}\left[\sum_{j=0}^{m} y_{j}(p) * w_{j k}(p)-\theta_{k}\right]$

where $m$ is the number of inputs of neuron $k$ in the output layer.

Step 3: Weight training

Update the weights in the backpropagation network propagating backward the errors associated with output neurons.

(a) Calculate the error gradient for the neurons in the output layer:

$$
\delta_{k}(p)=y_{k}(p) *\left[1-y_{k}(p)\right] * e_{k}(p)
$$

where

$$
e_{k}(p)=y_{d, k}(p)-y_{k}(p)
$$

Calculate the weight corrections

$$
\Delta w_{j k}(p)=\alpha * y_{j}(p) * \delta_{k}(p)
$$

Update the weights at the output neurons:

$$
w_{j k}(p+1)=w_{j k}(p)+\Delta w_{j k}(p)
$$

(b)Calculate the error gradient for the neurons in the hidden layer:

$$
\delta_{j}(p)=y_{j}(p) *\left[1-y_{j}(p)\right] * \sum_{k=0}^{\ell} \delta_{k}(p) * w_{j k}(p)
$$

Calculate the weight corrections

$$
\Delta w_{i j}(p)=\alpha * x_{i}(p) * \delta_{j}(p)
$$

Update the weights at the output neurons:

$$
w_{i j}(p+1)=w_{i j}(p)+\Delta w_{i j}(p)
$$

Step 4: Increase iteration $p$ by 1 , go back to step 2 , and repeat the process until the selected error criterion is satisfied.

\section{Results and discussion}

The ANN scheme to predict the weld bead geometry in underwater wet welding is shown in Figure 1. The aim is to map a set of input patterns to a corresponding set of output patterns by learning from past examples how the input parameters and output parameters relate. A feedforward backpropagation network trained with scaled conjugate gradient (SCG) backpropagation algorithm is used. The quality of the weld can be verified when the

\begin{tabular}{|c|c|}
\hline \multicolumn{2}{|l|}{ Program algorithm } \\
\hline \multicolumn{2}{|l|}{ load matlab.mat } \\
\hline \multicolumn{2}{|l|}{$\%$ inputs } \\
\hline I=DataProject(:,1); & $\mathrm{D}=$ DataProject(:;4); \\
\hline $\mathrm{U}=$ DataProject(:,2); & $\mathrm{H}=$ DataProject(:,5); \\
\hline v=DataProject(:,3); & $\mathrm{F}=[\mathrm{I} \cup \mathrm{\cup} \mathrm{DH}]$ \\
\hline \multicolumn{2}{|l|}{ \%outputs } \\
\hline \multicolumn{2}{|l|}{ W=DataProject(:,6); } \\
\hline $\mathrm{P}=$ DataProject(:,7); & $\mathrm{G}=[\mathrm{W}$ P R]; \\
\hline \multicolumn{2}{|l|}{$\mathrm{R}=$ DataProject(:,8); } \\
\hline \multicolumn{2}{|l|}{$\%$ training } \\
\hline$p=F(1: 12, ;) ;$ & $\mathrm{t}=\mathrm{G}(1: 12,:)$ \\
\hline \multicolumn{2}{|l|}{$\%$ testing } \\
\hline$X=F(13: 16,:) ;$ & $Z=[x \quad y]$ \\
\hline \multicolumn{2}{|l|}{$y=G(13: 16, ;) ;$} \\
\hline \multicolumn{2}{|l|}{$\%$ form the network } \\
\hline net=feedforwardnet([40],'trainscg'); & net.trainParam.max_fail=2000; \\
\hline net.trainParam.goal=0; \% error goal & net.trainParam.Ir=0.001; \\
\hline $\begin{array}{l}\text { net.trainParam.epochs }=3000 \text {; } \\
\% \text { maximum iterations }\end{array}$ & net.trainParam.mc $=0.9$; \\
\hline \multicolumn{2}{|l|}{$\begin{array}{l}\text { net.trainParam.show }=25 ; \% \text { showing } \\
\text { intervals }\end{array}$} \\
\hline \multicolumn{2}{|l|}{$\%$ Network initialization } \\
\hline net.initFcn='initlay'; & $\begin{array}{l}\text { [net,tr]=train }\left(\text { net, } \mathbf{p}^{\prime}, \mathrm{t}^{\prime}\right) \\
\% \text { training the net }\end{array}$ \\
\hline net.layers $\{1\}$.initFcn='initnw'; & view(net) \\
\hline \multicolumn{2}{|l|}{$\begin{array}{l}\text { net=init(net);\% initialize the net } \\
\text { (weights and biases initialized) }\end{array}$} \\
\hline \multicolumn{2}{|l|}{$\begin{array}{l}\% \text { simulating the network with } \\
\text { training inputs for testing }\end{array}$} \\
\hline$f=$ net $\left(x^{\prime}\right)$; & $f^{\prime}$ \\
\hline \multicolumn{2}{|l|}{$\%$ compare results/target } \\
\hline Error $=f^{\prime}-y$ & \\
\hline
\end{tabular}
training pattern fulfills the requirement for the accepted ranges of WPSF (penetration shape factor) $=W / P$ and WRFF (reinforcement form factor) $=W / R$. The accepted ranges for a weld with good quality are a maximized penetration to width ratio and minimized undercut and reinforcement.

\section{Table 2 Program algorithm}




\section{Design parameters}

The experimental data values in Table 1 for process parameters, water depth and bead geometry are the values used for the training of) the neural network. These values are from an experimental data adapted from the work of Shi et al. (2013). The error results for each testing are included in the modified table (Table 1). The errors in italics are the errors from the training which are big and not desirable. A smaller error tending to zero is desired or an actual zero which is however not so easy to achieve.

\section{Program algorithm}

There are five input parameters and three output parameters in this model (Table 2). The training (Figure 4) was done for all the sets of data, so also is the testing. The target is to achieve an error value of 0 . The size of the hidden layer was obtained by iterative adjustment while measuring the error during the neural network testing (Nagendra \& Khare 2006). The network for this study has two layers; there are 40 neurons in the hidden layer. In this study, the neural network should ideally be able to learn and understand the interaction between the welding process parameters. There are different training algorithms for different processes. The SCG backpropagation algorithm was used for the training of the network because it is suitable for the training of larger networks. Other training algorithms had the problem of overfitting caused by overtraining, resulting in memorization of input/output instead of analyzing them on the internal factors determined by the updated weights. The learning rate used is 0.001 and it gave satisfactory results. In artificial neural networks, a high learning rate may lead to overshooting, while a slow learning rate takes more time for the network to converge.

\section{Validation performance}

Epoch is a single presentation of each input/output data on the training set. It indicates the iteration at which the validation performance reached a minimum (Fahlman

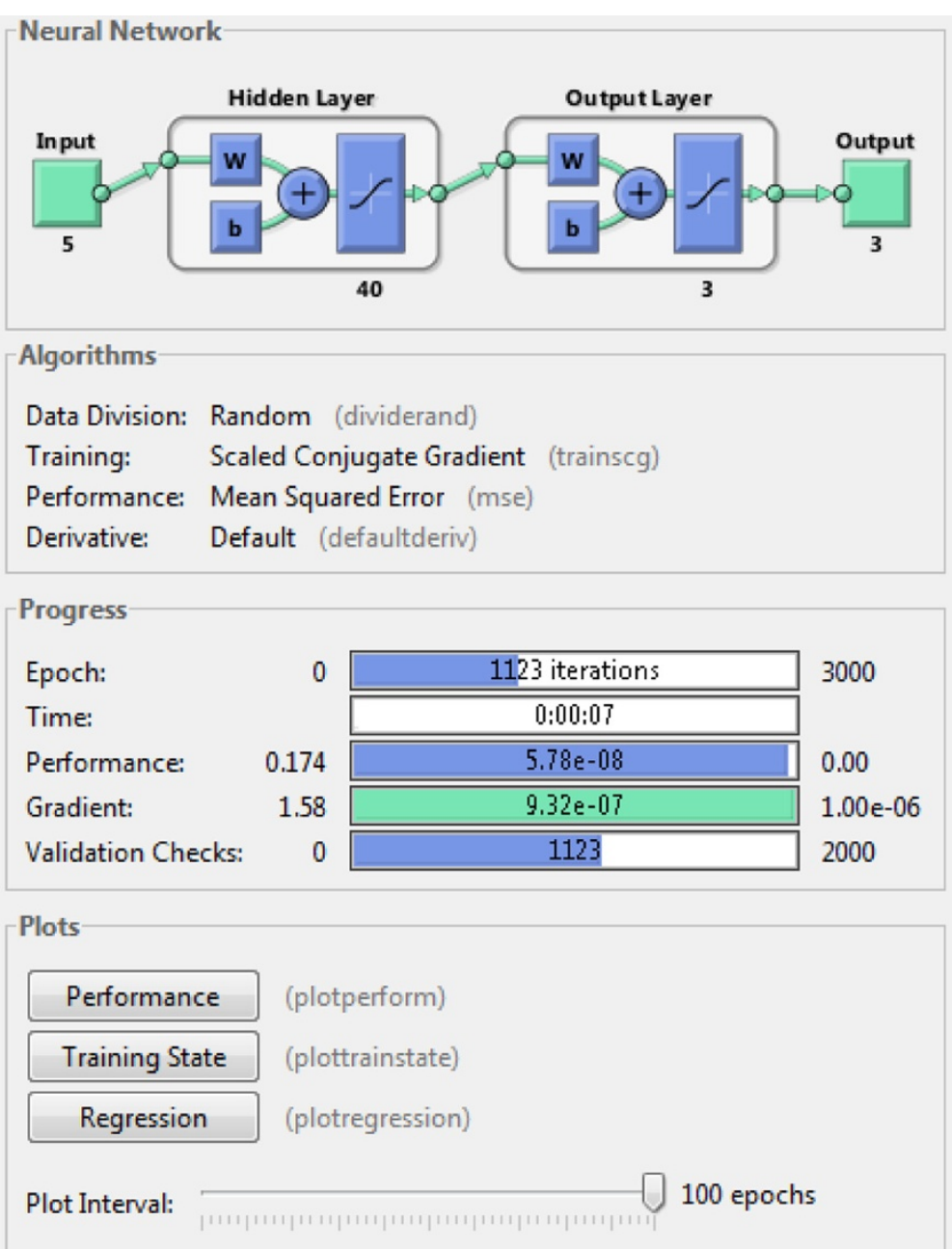

Figure 4 Neural network training tool. 

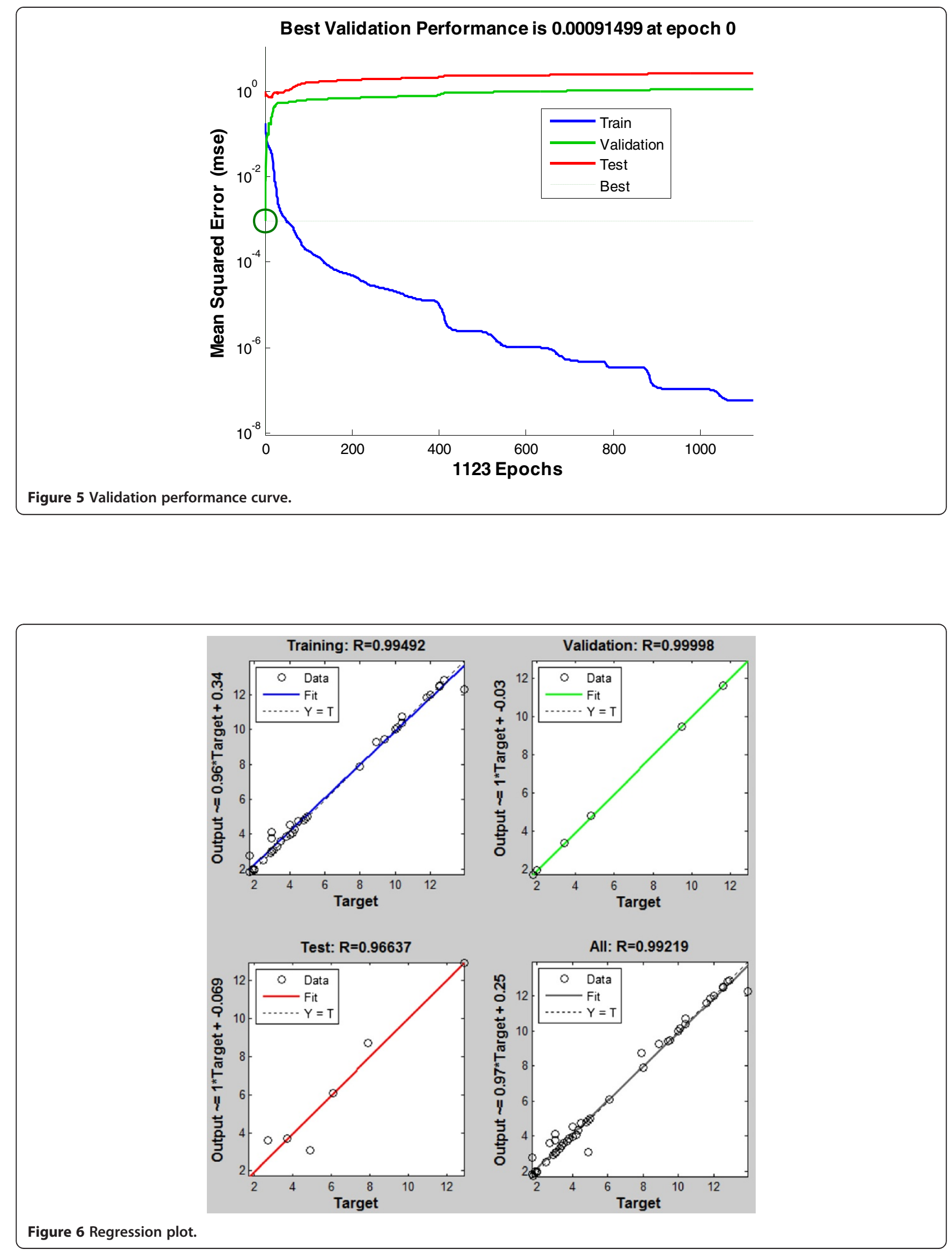
1988). The training continued for 1,123 more iteration before the training stopped. Figure 5 does not indicate any major problems with the training. The validation and test curve are very similar. If the curve had increased significantly before the validation curve increases, then it is possible that some overfitting might have occurred. The final mean squared error (MSE) is small, which is $9.1499 \mathrm{e}-4$ at zero epoch. The MSE is used to gauge the performance of the network. The MSE is an average of the squares of all the individual errors between the model and the real measurements. The MSE is useful for comparing different models with the same sets of data.

\section{Regression analysis}

This plot is used to validate the network performance. The regression plots in Figure 6 display the network outputs with respect to targets for training, validation, and test sets. For a perfect fit, the network outputs are equal to the targets. The fit for this problem is reasonably good for all data sets with $R$ values in each case at least 0.96637 . These results are achieved by retraining which changes the initial weights of the network. In this problem, $100 \%$ of the data sets were used for training, validation, and testing of the network generalization.

\section{Controller for underwater wet welding process}

Figure 7 is a proposed schematic diagram for a possible control of underwater wet welding in which the NN optimization of the welding process parameter can be applicable. The NN model in this paper will be an essential part in the control architecture of the proposed controller with the aim of designing a robust controller for underwater wet welding process, and further research work is necessary in this regard. The preliminary explanation of this possible controller is highlighted in this section. The control system is aimed at controlling the welding process parameters for different measured water depth $H$; the water depth is not a control parameter but a measured parameter as welding is being carried out at different water depth. The water depth for the welding process is measured as the depth changes. This change in the measured water depth consequently changes the welding process parameters which in turn alters the

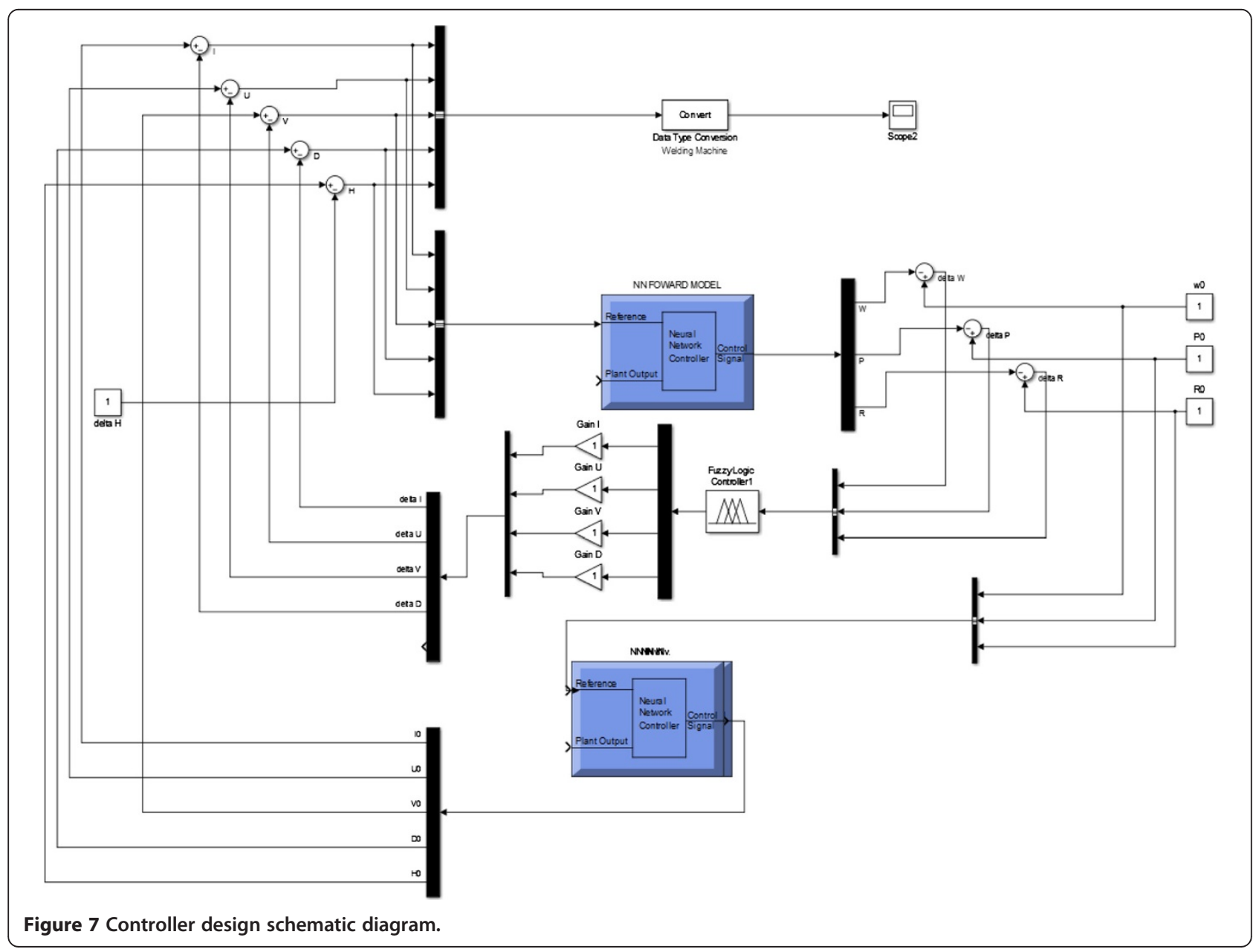


bead geometry $W, R$, and $P$. The fuzzy controller compensates for this change and modifies the welding process parameters $I, u, V$, and $D$. The inverse $\mathrm{NN}$ has a constant parameter value which is the desired bead geometry parameter as inputs to the inverse NN and best parameter of the welding process as the output from the inverse $\mathrm{NN}$. The error values for the training in experiment 1 from Table 1 are the best set of parameters because the errors for $W, R$, and $P$ are closer to zero compared to the values for the other experiments. The constant output parameters $I_{0}, U_{0}, v_{0}, D_{0}$, and $H_{0}$ which is the water depth at zero position from the inverse NN are summed up with the difference from the change in the output parameters $\Delta I, \Delta U, \Delta v, \Delta D$, respectively, of the fuzzy controller, and this compensates for the change in the welding process parameters and inputs the adjusted welding process parameter to the welding machine. For every measured change in the water depth $H$, a change in the bead geometry $\Delta W, \Delta P$, and $\Delta R$ which is the input to the fuzzy controller is modified and gives an output of $\Delta I, \Delta U, \Delta v$, and $\Delta D$. The welding process parameter from the welding machine is equal to the $\mathrm{NN}$ forward model, and as such, any change in the $\mathrm{NN}$ forward model is a subsequent change in the welding process itself. This control mechanism is a possible robust control process of the welding process and eliminates the need for online measurement of the weld bead geometry.

\section{Conclusions}

The optimization of the parameters that affect weld bead geometry during underwater welding can be done by artificial neural network training algorithm. In this study, the regression analysis show that the target follows closely the output as $R$ is at least $96 \%$ for training, testing, and validation. The trained neural network with satisfactory results can be used as a black box in the control system of the welding process. The effective optimization of the welding process parameter in underwater wet welding has the ability of welding with an optimized heat input and optimized arc length which will guarantee arc stability. The use of optimized process parameters enables the achievement of an optimized weld bead geometry which is a key factor in the soundness of welds. The control process for underwater welding as suggested in this paper requires further research so as to fully apply the NN optimization process.

\section{Competing interests}

The authors declare that they have no competing interests.

\section{Authors' contributions}

The main author JEO carried out the research and designed the neural network model and analyzed the training results and prepared the paper. HW was responsible for key technical supervision. PK and JM checked the paper and provided suggestions to improve the paper. All authors read and approved the final manuscript.
Received: 8 September 2014 Accepted: 5 November 2014

Published online: 21 November 2014

\section{References}

Al-Faruk, A, Hasib, A, Ahmed, N, Kumar Das, U. (2010). Prediction of weld bead geometry and penetration in electric arc welding using artificial neural networks. International Journal of Mechanical \& Mechatronics Engineering, 10 (4), 19-24.

AWS. (2010). "Underwater welding code". USA: AWS.

Brown, RT, \& Masubuchi, K. (1975). "Fundamental Research on Underwater Welding". In Welding research supplement (pp. 178-188).

Fahlman, SE. (1988). An empirical study of learning speed in backpropagation. USA: Carnegie Mellon University.

Johnson, RL. (1997). The Effect of Water Temperature on Underbead Cracking of Underwater Wet Weldments. California: Naval Postgraduate School.

Juang, SC, Tarng, YS, \& Lii, HR. (1998). A comparison between the backpropagation and counterpropagation networks in the modeling of TIG welding process. Journal of Material ocessing Technology, 75, 54-62.

Liu, S, Olson, DL, \& Ibarra, S. (1993). Underwater Welding. ASM Handbook, 6, 1010-1015.

Nagendra, SM, \& Khare, M. (2006). Artificial neural network approach for modelling nitrogen dioxide dispersion from vehicular exhaust emissions. Ecological Modelling, 190(1-2), 99-115.

Negnevetsky, M. (2005). Artificial Intelligence. UK: Addison Wesley.

Omajene, JE, Martikainen, J, Kah, P, \& Pirinen, M. (2014). Fundamental difficulties associated with underwater wet welding. International Journal of Engineering Research and Applications, 4(6), 26-31.

Shi, Y, Zheng, Z, \& Huang, J. (2013). "Sensitivity model for prediction of bead geometry in underwater wet flux cored arc welding". In Transaction of nonferrous metals society of China (pp. 1977-1984).

doi:10.1186/s40712-014-0026-3

Cite this article as: Omajene et al:: Optimization of underwater wet welding process parameters using neural network. International Journal of Mechanical and Materials Engineering 2014 9:26.

\section{Submit your manuscript to a SpringerOpen ${ }^{\circ}$ journal and benefit from:}

- Convenient online submission

- Rigorous peer review

- Immediate publication on acceptance

- Open access: articles freely available online

- High visibility within the field

- Retaining the copyright to your article

Submit your next manuscript at springeropen.com 